\title{
Online Medya Okuryazarlığının Yetişkinler İçin Önemi “Online Haber Sitelerindeki Bannerlara Yönelik Bir İnceleme"
}

\author{
Nilüfer SEZER, \\ Prof.Dr., İstanbul Ünv., İletişim Fakültesi, nsezer@istanbul.edu.tr \\ Nuray YILMAZ SERT, \\ Dr., nuray.ylmz@gmail.com
}

ÖZET

Küreselleşme ve iletişim teknolojilerindeki gelişmeler, geleneksel anlamdaki okuryazarlık kavramının yeni uygulamaları da kapsayacak şekilde genişlemesine yol açmıştır. Doğrudan internete gönderme yapan ve sadece internet yoluyla karşı karşıya kaldığımız bilgi ya da mesajların çözümlenmesini kapsayan online medya okuryazarlı̆̆ı konusu da yeni okuryazarlık uygulamalarından biri olarak giderek daha büyük önem kazanmaktadır. Medya okuryazarlı̆g araştırmalarının birçoğunun medyanın çocuklar üzerindeki olumsuz etkileriyle ilgili olduğu ve bu konuda çocukları ve ailelerini bilinçlendirmeyi amaçladiğı görülmektedir. Bu durumun temel nedeni, çocukların etkiye en açık grubu oluşturmalarıdır. Fakat özellikle internetin sadece çocuklar üzerinde değil yetişkinler üzerinde de bir çok olumsuz etkilerinin olması yetişkinler için online medya okuryazarlığıyla ilgili çalışmaların gerekliliğini ve önemini ortaya koymaktadır. Bu makale yetişkinler için online medya okuryazarlı̆̆l konusunun önemini haber siteleri üzerinden incelemeyi amaçlamaktadır. Araştırmanın varsayımına göre, online haber sitelerinde yer alan çeşitli ürün, hizmet vs. reklamına ve satışına yönelik bannerlar; kullanıcıları asıl amaçlarından uzaklaştırarak tamamen tüketime yönlendiren farkh ortamlara taşımaktadır. Bu varsayıma yönelik olarak online haber sitelerinin ana sayfalarında yer alan bannerlar incelenmiş ve sonuçları online medya okuryazarlığı bağlamında değerlendirilmiştir.

Anahtar Kelimeler: Online Medya, Medya Okuryazarliğı, İnternet Bannerları

\section{The Importance Of Online Media Literacy For Adults \\ "A Review Intended for Baners in Online News Sites"}

ABSTRACT Globalization and advances in communication technologies has led to the expansion in the traditional sense of the concept of literacy in the manner that include the new applications. The issue of media literacy -which is referring directly to the Internet and covering the resolution of online information or messages that only confronted by internet-is becoming to more and more important as one of the new literacy practices. It is observed that many of the media literacy researchs are about the negative effects of media on children and aimed to raise the awareness of 
the children and their families. The main reason of this situation is that, children are most open to influence. But especially internet have very kinf of negative effects not just on children but also on aduls. So it reveals the necessity and importance of studies on the online media literacy for adults. This article aims to examine the importance of the issue of online media literacy for adults by the way of news sites. According to assumption of research, banners for advertising or sales of various products, services, etc. on online news sites remove users away from their main aims and carry them different environments that completely direct to consumption. For this assumption, banners in the home pages of online new sites were investigated and the results were evaluated in the context of online media literacy.

Key Words: Online Media, Media Literacy, Internet Banners

\section{GİRiş}

Medya sistemlerinin daha karmaşık hale gelmesiyle birlikte, İngilizce media literacy teriminden dilimize çevrilen ve temelde medya mesajlarının doğru algılanmasıyla ilgili olan, medya okuryazarlığı konusunun giderek daha fazla önem kazandığı görülmektedir. Medya genel anlamıyla, tüm iletişim ortam ve araçlarını içine alan bir kavramdır. Okuryazarlık kavramının ise en temel kullanımı, bireylerin yazılı metinleri okuyabilmeleri ve yazabilmeleriyle ilgidir. Fakat teknolojideki gelişmelerle birlikte iletişim araçlarının çeşitlenmesi ve mesajların farklı medya ortamlarından aktarılıyor olması bireylerin çoklu okuryazarlık becerisine sahip olmalarını gerektirmektedir. Online medya okuryazarlığı da bunlar arasında öne çıkan konulardan biri olarak görülmektedir.

\subsection{Online Medya Kavramı}

Katılımcı demokratik toplumlarda kamuoyunu oluşturma görevini üstlenen medya, iletişim teknolojilerinde yaşanan gelişmelerle birlikte geleneksel medya ve yeni medya olmak üzere çift başlı bir organa dönüşmüştür. Bunun sonucunda haber alma, bilgilendirme, eğitme ve eğlendirme gibi temel işlevleri aynı olmakla birlikte bunların işleyiş ve uygulama biçimlerinde ciddi değişiklikler yaşanmıştır. Öncelikle yeni medyanın dijital yapısı geleneksel medya araçlarının tek yönlü akışını bozmuştur. Yeni medya araçlarının içerikleri, sadece üreticiden tüketiciye ya da izlerkitleye doğru tek yönlü değil çok yönlü bir akış göstermektedir. Geleneksel medya araçlarında üreticinin karşısında tüketici ya da izlerkitle olarak tanımlanan edilgen bir kesim bulunurken buna karşın yeni medya araçlarında üretime aktif olarak katılan kullanıcılar yer almaktadır. Bu kullanıcılar tarafından üretilen ve dijital iletişim kanalları üzerinden yayınlanan içeriklerin zaman zaman geleneksel medya araçlarında sunulan ana haber bültenlerine dahi konu olduğu görülmektedir. Böylelikle kendi medya ortamını oluşturan yeni iletişim teknolojilerinin, geleneksel medyayı da 
etkilediğini söylemek mümkündür. $\mathrm{Bu}$ yeni ortam çoğunlukla dijital medya olarak adlandirılmaktadir.

Kavram olarak dijital medya; radyo, televizyon, gazete, sinema, bilgisayar, internet ve dijital hale dönüştürülmüş tüm medya araçlarını kapsamaktadır. Online medya ise, dijital medya araçlarından sadece biri olan internete gönderme yapmaktadır. Dolayısıyla bu çalışmaya konu olan online medya okuryazarlığı konusu internetle sınırlandırılmış bir kavramdır, zaman zaman daha geniş kapsamlı kullanımları görülse de aslında içerik olarak diğer dijital medya araçlarını kapsamamaktadır. Bu bağlamda interneti online iletişimin aracı olarak tanımlayan Kelleher (2007:4-8), online medyanın unsurlarını onbir madde halinde aşağıdaki şekilde sinıflandırmaktadır:

İnternet: İnternet, kamuya açık küresel bir ağdır. Herbiri birbirine bağlı bilgisayarlar, kablolar, kablolu ya da kablosuz cihazlardan oluşan bu sistem, insanlar ve makinalar aracılığıyla dünya genelinde bilgi alışverişinin sağlanmasına yardımcı olmaktadır (Kelleher,2007:5). Başka bir anlatımla internet, gittikçe büyüyen bir iletişim ağıdır.

WWW (World Wide Web): Kısaca web, yazı resim, ses, video, animasyon gibi birçok farklı yapıdaki verilere kompakt ve etkileşimli bir şekilde ulaşmamızı sağlayan çoklu bir hiper ortam sistemidir. Hiper ortam, bir dokümandan başka bir dokümanın çağırılmasına olanak sağlar ve bu ortamdaki her nesne, başka bir nesneyi çağırabilir (link edebilir) (İnan,2000:72).

Dosya Aktarım Protokolü (FTP-File Transfer Protocol): Dosya aktarım protokolü kısaca FTP, kullanıcıların dosyaları bir bilgisayar sunucusuna koymalarını sağlamaktadır ve böylelikle diğer insanlar daha sonra farklı yerlerden bu dosyalara erişebilmektedir. Bu dosyaların internet üzerindeki aktarımı web tarama ve web yükleme yoluyla olmaktadır. Bir FTP programı aynı zamanda bir web tarayıcısı yerine kullanılabilmektedir. Bu tarz bir dosya aktarım sitesinin URL adresi standart olan $h t t p$ (hiper metin aktarım protokolü) yerine ftp ile başlamaktadır. Dosya aktarımları şifrelenebileceği gibi FTP adresini bilen tüm bilgisayar kullanıcılarının erişimine açık da olabilmektedir (Kelleher,2007:5).

E-posta: E-postalar, elektronik aktarıma uygun olarak biçimlendirilmiş (aynı zamanda metin, resim, ses ve video dosyaları gibi bir dizi eklentileri de olabilen) mesajları oluşturmak, göndermek ve almak için kullanıcılara olanak tanıyan programlarıdır. E-posta genellikle eşzamanlı olmayan bir iletişim biçimi olarak düşünülmektedir. Çünkü e-posta yoluyla iletişim kurabilmek için alıcı ve göndericinin aynı anda çevirimiçi olmaları gerekmemektedir (Kelleher,2007:5).

> Sohbetler (Chats) ve Anlık Mesajlaşmalar: İnternette, birebir ya da birden çoğa iletişim için kullanılabilen ve e-posta programları gibi çalışan sohbet ve anlık mesaj aktarım sistemleri mevcuttur. Bu sistemeler aynı zamanda bireylerin gönderici ve alıcı olarak katılımına göre çoktan çoğa iletişim için de kullanılabilir. Online bağlamda kullanılan sohbet (chat) teriminin en temel farklılığı metin temelli anlık bir iletişim olmasıdır. Yine de sohbetler ve anlık mesajlaşmalar telefon konuşmaları ya da yüzyüze iletişim gibi tümüyle anlık sayılmazlar. Çünkü mesajların yazılması ve gönderilmesi zaman almaktadır (Kelleher,2007:6).

İnternet Forumları: Bunlar bazen tartışma forumları, duyuru tahtası sistemleri, haber grupları ya da mesaj tahtaları olarakta adlandırılmaktadır. Bu sistemler insanlara yorum 
yapabilecekleri ya da soru sorabilecekleri iletişimsel davranışa dönüşen sanal ortamlar sunmaktadır. Sohbetlerden farklı olarak eşzamansız bir iletişim biçimi olan forumlar genellikle belirli bir konu üzerinden oluşturulmaktadır (Kelleher,2007:6).

> İntranet ve Extranet Uygulamaları: İntranet, bir kuruluşun iç kullanımı için oluşturulmuş bilgi ağı sistemi olarak tanımlanmaktadır. Halka açık bir web sitesi ile aynı genel kuralları kullanmakla birlikte sadece çalışanlar ve kuruluşun yetkili aracıları için erişilebilir bir uygulamadır. İntranetin aksine, extranet ise yetkili site dışı kullanıcılar için de erişilebilir durumdadır. Bu kullanıcılar kuruluş ile işbirliği içinde olan tedarikçiler, müşteriler, işletmeler vs. olabilir. Bilgi paylaşımı ve üyeler arasındaki iletişim için her iki uygulamada da geçerli bir kullanıcı adı ve parola gerekmektedir (http://www.e-ticaret.co.uk/intranet-veextranet-nedir/).

> İçerik Yönetim Sistemleri (CMS-Content Management System): İçerik yönetim sistemleri, sayfa sahibinin ve yetki verilmiş diğer kullanıcıların özel hesap bilgileri (kullanıcı adı, parola....) ile ulaşabildiği Sayfa Yönetim Panelini kullanarak web sayfasında yer alan içeriği (yazı, resim, müzik, dosyalar vs...) değiştirebildiği, yenilerini ekleyebildiği programlardır (http://iys.inonu.edu.tr/?web=bidb\&mw=54). Dünya genelinde tüm insanların içerik ekleme, değiştirme ya da silme yapabilmesine olanak tanıyan Wikipedia'nın da kullanmış olduğu wiki, bir içerik yönetim sistemidir.

Bloglar: Blog, ingilizce weblog sözcügüün̈ kısaltılmış ve yaygın kullanılan şeklidir. Web 2'yle birlikte ortaya çıkmış, 2003 yılında Google'ın blogger sitesini satın almasıyla birlikte popüler hale gelmiştir. Web günlüğü olarak tanımlanan bloglar için Türkçe'de "açıkgünlük”, “ağ günlüğü", "e-günlük” gibi bazı isimler de kullanılmaktadır. Kurulum aşamasında çok ilgi görmeyeceği düşünülen blog siteleri bugün gündem yaratma gücünü elde etmişlerdir. Blogların küçülmüş haline ise microblog denilmektedir. Bloglardan tek farkı paylaşılan bilgi, düşünce, haber vs. kısa ve anlıktır. Microblogların en bilineni ise Twitter'dır (http://www.ekatalog.com.tr/blog-nedir.html).

> Web Sayfası Bildirimcileri: Web sayfası bildirimcileri (haber bildirimcisi ya da içerik besleme adı da verilir ), web sitelerinin içerik ve güncellemelerini kolaylıkla izlemek için kullanılmaktadır. Bu verilerin otomotik olarak düzenlenmesi ve görüntülenmesi için örneğin google reader gibi bir bildirimci okuyucu kullanmak ve her web sitesinin kendi bildirimcisine abone olmak gerekmektedir. RSS ve Atom, farklı internet sitelerinin güncelleme ve içeriklerini, bu siteleri ayrı ayrı ziyaret etmek zorunda kalmadan, tek bir ortamdan topluca takip etmeyi sağlayan bildirimci biçimleridir

İzleme ve Ping Atma Programları: Blog gibi online medya biçimleriyle kullanılan otomatik bir bağlantı (linking) biçimidir. Bir blog yazarı kendi postundan diğer bir blog yazarıyla bağlantı kurduğunda eğer her iki blogta geri izleme teknolojisiyle destekleniyorsa, bağlantı kurulan bloğun ağda olup olmadığını görebilir. Buna "pink atma" denmektedir. Bu şekilde bir blog yazarı pink attığ blogdaki yeni içerikleri otomatik olarak takip edebilir ayrıca blog ziyaretçileri birbirine bağlı bloglar arasında kolayca gezinebilir (Kelleher,2007:8). Ping atma, sadece bloglar arasında gerçekleşmez. Google gibi arama motorlarına da ping atılarak yeni girilen içerik veri tabanlarına yazdırılabilir.

Kelleher'in yapmış olduğu yukarıdaki sınıflandırma online medyanın haber üretimi, iletimi ve erişimi için kullandığı temel araçları içermektedir. Fakat her geçen gün teknolojik 
gelişmelere bir yenisi eklenmektedir, dolayısıyla online medyanın unsurları da çeşitlenerek artmaya devam etmektedir.

\subsection{Medya Eğitiminden Online Medya Okuryazarlığına}

Türkçe'de okuryazarlık, kavramı "okuyup yazabilme, kendini yazarak ifade edebilme, Türkçe harflerle yazılı materyali okuyabilme becerisine sahip olma" olarak açımlanmaktadır (Taşkıran,2007:89). Kellner'e göre bir kişinin kültür ve topluma katılımını arttıran okuryazarlık, belli metin türleri ve eserleri okuyabilmek, yorumlayabilmek ve üretebilmek için bilgi ve becerilerin kazanılması anlamına gelmektedir (Kellner\&Share,2005:369). Okuma yazama becerileri, yirminci yüzyılın ortalarından itibaren görsel işitsel malzemelerin okunabilmesini de içine almıştır. Bugün ise, bilgi ve iletişim teknolojolerindeki büyük gelişmeler yeni okuryazarlık biçimleri ortaya çıkarmıştır (Livingstone,2004:3).

Günümüzde medya metinleri görsel (durağan ya da hareketli), işitsel (ses, müzik ya da konuşma) ve yazılı dilde olabilmektedir. Çeşitli şekillerde iletilen medya mesajları karşısında bireylere bilinçlilik kazandırmayı amaçlayan medya eğitimi dolayısıyla çok geniş tabanlı bir yeterlilik geliştirmeyi amaçlamaktadır. Bu yeterlilik genellikle bir okuryazarlık biçimi olarak tanımlanmaktadır ve modern anlamıla medya okuryazarlı̆̆ $ı$ olarak kullanılmaktadır (Buckingham,2003:4). Dolayısiyla medya okuryazarı, medyada yeniden kurgulanan iletileri ayırtedebilmek ve algılayabilmek, onunla ilgili yorumlarda bulunabilmek için ayrı bir beceri, altyapı bilgisi ve eğitsel organizasyon gerektiren bir eğitim sürecinin sonucu olarak medya yetkini sıfatını kazanan kişiyi betimleyen bir terimdir (Taşkıran,2007:7). Medya eğitimi ise, iletişimsel becerilerin geliştirilebilmesi, eleştirel düşünebilme, medya metinlerini algılama, yorumlama, analiz edebilme ve değerlendirebilme, farklı medya teknolojilerini kullanarak kendini ifade edebilmenin çeşitli biçimlerini öğretme gibi süreçleri içermektedir. Medya okuryazarlığ $\mathrm{bu}$ sürecin sonucudur ve bir insana televizyon, radyo, gazete, sinema, internet vb... bilgi kaynaklarını aktif olarak nasıl kullanacağı konusunda yardımcı olmaktadır (Federov,2003:1). Medya okuryazarlığı konusunda uzman olan Hobbs, medya okuryazarlığını dört süreçte açıklamaktadır. Bunlar (Hobbs,1997:166):

Erişim: Bir bireyin medyaya erişiminin mümkün olması gerekir - bir gazeteyi nereden alabiceğini bilmek, gazeteyi alabilmek için paraya sahip olmak, okuyabilmek ve sözcükler deşifre edebilmek bilgiye erişim için temel becerilerdir. Medyanın en modern formu olan bilgisayarlar ise çok daha fazla yeterlilik gerektirmektedir.

Analiz: Bireylerin sadece bilgiye erişmeleri değil onları yorumlayabilmeleri de önemlidir. Yazarın amacı nedir? Ne söylemek istiyor? Yazarın niyeti nedir? Birey aynı zamanda bilginin bağlamsal yönünü de düşünmelidir. Ne zaman yazılmıştır? Bazı şeylerin yer almasında hangi şartlar neden olmuştur? vs...

Değerlendirme: Bireyler için gerçekte hangi bilgi gereklidir? Bir gazetede hangi makaleler okunmalı hangileri gözardı edilmelidir?

> İletişim: İletişim en önemli medya yetkinliği olarak kabul edilmektedir. Bu, haberi veren ve alıcının birbirlerini anlaması yani kelime ve harfleri deşifre etmesi değil mesajın bütününü anlaması anlamına gelmektedir. Bunun için dilin ve gramerin doğru kullanılmasının yanısıra bazı özel yetkinlikler de gerekmektedir. Örneğin haberci, yayın 
sırasında herkesin anlayabileceği bir grafik kullanabilir, alıcının da bu grafiği anlaması gerekir.

Sonuçta en genel anlamıyla medya okuryazarlığı, yazılı ve yazılı olmayan, farklı medya araçlarındaki (televizyon, video, sinema, reklâmlar, internet v.s...) mesajlara ulaşma, bunları analiz ederek çözümleme, değerlendirme ve iletme yeteneği olarak tanımlanmaktadır. Bu tanımdan da anlaşılabileceği gibi medya okuryazarlığı kavramının aslında bir yandan medya unsurları oluşturarak bunları iletme diğer yandan da iletilen medya unsurlarını alırken çözümleyebilme becerisini içerdiği görülmektedir. Fakat medya okuryazarlığ denildiğinde; bu iki içerikten daha çok medyayı çözümleyebilme becerisinin anlaşıldığ görülmektedir (http://www.medyaokuryazarligi.org.tr/nedir.html).

Medyayı çözümleyebilmek için eğitimcilerin ve savunucu grupların birçoğu tarafından kullanılan sekiz temel prensip öne sürülmektedir. 1980'lerden bu yana medya okuryazarlı̆̆ konusuna odaklanılması, sınırlarının belirlenmesi ve kapsamının tanımlanması çabalarının bir sonucu olarak gelişen bu prensipler Patricia Aufderheide tarafından derlenmiştir. Medya okuryazarlığının ilk prensibine göre, tüm medya kurgulardan oluşmaktadır. Her ne kadar medya sadece dünyayı yansıtıyor gibi görünse de aslında multimedya etkileri aracıllğıyla dikkatle oluşturulmaktadır. Artan teknolojik gelişmeler birçok medya metinindeki "eklentileri" görünmez kılmakta ve bizim medyayı gerçekliğin üreticisi veya sağduyu oluşturucusu olarak görmemizi zorlaştırmaktadır (Frechette,2002:26). Başka bir ifadeyle medya, sadece diş gerçekliği yansıtmamakta aksine birçok belirleyici faktörün sonucu olarak dikkatle hazırlanmış kurgular sunmaktadır (http://www.medialit.org/readingroom/canadas-key-concepts-media-literacy). Medya okuryazarlığı, bu kurguları çözümleyerek medyadaki eklentilerin görünür olmasını sağlamaktadır. Medya okuryazarlığının ikinci prensibi medyanın gerçeklik inşaa etmesidir yani gerçeklik sosyal olarak inşaa edilmektedir. Okuryazarlık teorisi, aydınlanmış zihinsel bir süreç olarak "doğru" olanın ortaya çıkarılmasıyla ilgili bir kaygı içermektedir. Fakat gerçeklik sınırının ötesine geçmemekle birlikte "doğru", günlük yaşamımızda oluşturulan bir olgudur (Frechette,2002:26). Etrafımızdaki dünya ve onun işleyişiyle ilgili kişisel algılarımızın büyük bir çoğunluğu medya mesajlarına (örneğin medya da yer alan açıklamalar, fikirler, bakış açıları vs.) dayanmaktadır. Dolayısıyla gerçeklik algımız büyük bir çoğunlukla medya tarafından oluşturulmaktadır (http://www.medienabc.org/page5/page7/page7.html). Medya okuryazarlığı, gerçekliği medyanın öngördüğü aynı gerçeklikle görmek, deneyimlemek ya da ilişkilendirmek zorunda olmadığımız üzerinde durmaktadır. Üçüncü faktör, medyadaki anlamların izlerkitle tarafından tartışılır olmasıdır. Buna, izlerkitle analizi'de denilmektedir. Eğitim, cinsiyet, yaş, ırk ve etnisite gibi özelliklerin yanında kişisel zevkeler, istek ya da korkular medya mesajlarının anlamlandırılmasını etkilemektedir. Dolayısıyla her ne kadar medya gerçekliğin inşaası için birçok malzeme sağlasa da çeşitli faktörlere bağlı olarak her bir medya tüketicisi medyadan birbirinden farklı anlamlar ya da deneyimler edinmektedir. Medyada verilen bir mesajı iki kişinin tam olarak aynı şekilde yorumlaması mümkün değildir. Basit bir ifadeyle "anlam", çeşitli şekillerde tartışılabilir bir olgudur (Frechette,2002:27). Dördüncü prensip, medya mesajlarının ticari etkileri olmasıyla ilgilidir. Medya okuryazarlığı, medyanın ticari kaygılardan etkilendiğini ve bu kaygıların medya dağıtım, teknik ve içeriklerine yansıması konusundaki bilinçliliği geliştirmeyi 
amaçlamaktadır. Birçok medya kuruluşu bir işletmedir ve kar elde etmesi gerekmektedir. Dolayısıyla medyanın ekonomik işlevinin medyada üretilen içerikler üzerinde etkisi vardır (http://www.medialit.org/reading-room/canadas-key-concepts-media-literacy). Ö̈rneğin ratingler, televizyon programlarını değerlendirmek için bir araç olarak kullanılmaktadır ve izlerkitlenin büyüklüğü bir programın yayına devam edip etmemesini belirlemektedir. Aynı şekilde bir programın izlerkitlesinin demografik özellikleri de reklam verenler için önemlidir. Temel olarak medya okuryazarlığı izlerkitlenin, bir programın içeriğinden kar elde etmeyi gözeten reklamverenlere satılmak üzere "pazarlanabilir" gruplara ayrıldığının bilincine varılmasını sağlamaktadır. Ayrıca içerikle ilgili medyanın kurumsal mülküyet etkisini de incelemek gerekmektedir. Özellikle 1980'lerden sonra hem üretim hem dağıtım kanalları üzerinde çok güçlü küresel tekeller ortaya çıkmış ve medya türlerindeki çeşitlilik kaybolmuştur. Böylece üretilecek medya içerikleriyle ilgili kararların alınması birkaç güçlü grubun eline geçmiştir. Doğal olarak ekonomik medya kuruluşu, bir haberin seçimini ve o habere bakış açısını doğrudan etkilemektedir (Frechette,2002:27). Medya okuryazarlığının beşinci prensibi, medyanın ideoloji ve değer içerikli mesajlar iletiyor olmasıdır. Bütün medya ürünleri belirli değer ve yaşam biçimlerinin bir anlamda reklamını yapmaktadır. Anaakım medya, açıkça ya da dolaylı olarak, koşulsuz vatanseverlik, otoritenin kabulü, kadının rolü, tüketicilik erdemi ve iyi bir yaşamın nitelikleri gibi bazı konularda ideolojik mesajlar iletmektedir (http://www.medienabc.org/page5/page7/page7.html). İdeoloji dağıtıcısı olarak medya, çoğunlukla var olan sosyal yapıyı pekiştirmek için bazı inanç ve değer sitemlerinin savunuculuğunu üstlenmektedir. Örneğin iş dünyası, okul, hükümet, din gibi egemen sosyal yapılar içinde yaygın olarak kabul gören fikirler medya yoluyla güçlendirilmektedir. Medya okuyazarlığı, "kutunun dişında" -televizyon kutusu, radyo kutusu, bilgisayar kutusudüşünebilmemiz için kendimizle sürekli mücadele etmemizi gerektirmektedir. Böylelikle toplumumuzdaki değer sistemlerini ve temel ideolojik mesajları ayırabiliriz. Bir toplumdaki güçlü bireylerin, grupların, sınıf ve kültürün ihtiyaç ya da hedeflerini yansıtan medyanın aynı zamanda sosyal ve politik etkileri de vardır. Altıncı prensibe göre medya okuryazarlığ medyadan kaynaklanan sosyal ve politik etkilerin farkındalığını artırmaktadır (Frechette,2002:28). Medya, sosyal ve politik konularda toplumsal değişimin oluşmasını hızlandırmaktadır. Örneğin AIDS salgını, Afrika'daki kıtlık, sivil hakları gibi konulardaki kaygılara bizi de dahil etmek yoluyla ulusal ve uluslararası konularda sağduyu kazandırarak McLuhan'ın'da bahsettiği global köye dönüşmemizi sağlamaktadır Medya okuryazarlığının yedinci prensibine göre medya mesajlarındaki biçim ve içerik birbiriyle yakından ilişkilidir. Yine McLuhan'ın da belirtmiş olduğu gibi her medya aracının kendi dil yapısı vardır ve gerçekliği kendine özgü bir şekilde düzenlemektedir. Örneğin televizyonda yangın, deprem, protesto gibi olayların görüntülerine yer verilirken radyoda konuyla ilgili yetkili kişilerin konuşmaları daha fazla yer almaktadır. Yazılı basın ise, bir yangının nasıl başladığ1 ya da protestoların nedenleri gibi bir konunun arka planı daha detaylı olarak sunabilir. Dolayısıyla aynı olay farklı medya araçlarında farklı etkiler yaratabilmektedir. Sekizinci ve son prensip, her medya aracının estetik açıdan eşsiz bir biçimi olduğunu belirtmektedir. Medya eğitimi sadece medya metinlerini ve bunların sosyal ve kültürel açıdan etkilerini anlamaktan ibaret değil aynı zamanda bunlardan nasıl keyif alacağımız ve nasıl üreteceğimizle ilgilidir. Her medya aracının beğeni kazanan farklı biçim ve etkileri vardır. Beğeni kazanan biçim ve etkilerin nasıl oluşturulduğunun bilincinde olmak bizim medyadan alacağımız keyfi de artıracaktır. Örneğin canlı yayın açısından televizyon en iyi 
araçtır. Sporla ilgili bir olayı televizyonda canlı olarak izlemek, onunla ilgili okumak ya da daha sonra tekrarın izlemekten daha heyecanlı ve zevklidir. Televizyon aynı zamanda olimpiyatların açılışı ya da Leydi Diana'nın cenaze töreni gibi dünyadaki olaylarla ilgili gündemlere gerçek anlamda bir katılım ve paylaşım duygusu vermektedir (http://www.medialit.org/reading-room/canadas-key-concepts-media-literacy).

Medyanın yapısı ve etkileri gözönüne alınarak belirlenmiş olan bu sekiz temel prensipten yola çıkılarak medya hakkında tamamıyla olumsuz yargılara varılmamalıdır. Özellikle eğitimin birçok alanında medya yardımcı bir araç olarak kullanılmaktadır. Hatta medya eğitimi ve medya okuryazarlığı arasındaki ilişki incelendiğinde medyanın kendisinin de medya okuryazarlığı konusunu desteklediği ve izlerkitlenin eleştirel bir bakış açısına sahip olabilmesinde aracı konumda olduğu görülmektedir. Ülkemizde, Radyo Televizyon Üstkurulu ve Milli Eğitim Bakanlığı tarafından hazırlanan ve televizyon kanallarında yayınlanan Medya Okuryazarlı̆̆ı Kamu Spotu'nu bunun en iyi örneklerinden biri olarak değerlendirmek mümkündür.

Değerli Veliler,

Çocuklarınızın televizyon izlerken, internet kullanırken, gazete okurken, radyo dinlerken seçici olmasını, gerçek ile kurguyu ayırt etmesini, kontrollü izleyici olmasını, olumsuz etkilerden korunmasını, doğru şekilde faydalanmasını, yorum yapabilmesini, eleştirel bakabilmesini istiyorsanız şimdi bunu sağlamak sizin elinizde. Radyo ve Televizyon Üst Kurulu ve Milli Eğitim Bakanlığı işbirliği ile ilkögretim okullarında seçmeli medya okuryazarlığı dersi okutulacaktır. Çocuklarınızın medyayı doğru anlayabilmesi için medya okuryazarlığı dersini seçin.

Medya Okuryazarlığı Kamu Spotu Metni (http://www.ajans01.com/video/25-medya-okuryazarligi-kamu-spotu.html )

Medya okuryazarlı̆̆ıyla ilgili yapılan çalışmaların birçoğunda olduğu gibi yukarıdaki çalışma da çocukları konu almaktadır ve medyanın olumsuz etkilerinden çocukları koruyabilmek için aileleri bilinçlendirip yönlendirmeyi amaçlamaktadır. Bunun en temel nedeni çocukların örneğin televizyon karşısında etkiye en açı, en hassas grubu oluşturuyor olmasıdır. Ayrıca, gerçeklik ile kurguyu ayırt edebicek bir yaşta ve donanımda olmadıklarından dolayı, gördükleri her şeyi gerçeklik olarak algılayıp olabilirliğine inanmalarıdır (http://www.medyaokuryazarligi.org.tr/neden.html). Bu bağlamda Jenkins, çocukların medya ile olan ilişkilerinde, anlamlı seçimler yapmalarında ve seçimlerinin sonuçlarını tahmin etme sürecinde ailelerinin önemli katkısına ve rolüne dikkat çekmektedir (aktaran Sezen,2011:350). Tüm bu nedenlerden dolayı medya okuryazarlığı ile ilgili çalışmalar öncelikle çocukları ve ailelerini ele almaktadır. Fakat özellikle yeni medya araçlarından internetin, sadece çocuklar üzerinde değil yaşamlarının ileri ki dönemlerinde bu araçla karşılaşmış olan yetişkinler üzerinde de birçok olumsuz etkileri olduğu 
bilinmektedir. $\mathrm{Bu}$ da yetişkinler için online medya okuryazarlığı konusunda yapılan çalışmaların önemini ve gerekliliğini ortaya koymaktadır.

\section{ONLINE HABER SİTELERINDE YER ALAN BANNERLARA YÖNELIKK BİR İNCELEME}

Tablet bilgisayarlar ve akıllı telefonlar sayesinde taşınabilir olması interneti günümüzün en önemli haber kaynağı haline gelmiştir. Amerika Birleşik Devletleri'nde yapılan bir araştırmaya göre, kullanıcılarının büyük bir çoğunluğu haberleri internet üzerinden takip etmektedir. Online haber okumak, maillere bakmaktan sonra gerçekleştirilen ikinci aktivitedir ve kullanıcıların \% 80'ni online haberlere en az geleneksel haber kanalları kadar güvendiklerini belirtmektedir (Philips,2001:171). Kısaca hızla yaygınlaşmasına bağlı olarak internet kullanıcıları gazete ve televizyon kadar haber sitelerine de önem vermeye başlamışlardır. Bu bağlamda haber sitelerinin yerel, ulusal ve uluslararası olmak üzere siyaset, ekonomi, spor, toplum, yaşam, sağlık vb. ilişkin haberlerin edinildiği sanal mekanlar olarak ilgi düzeyi önemli ölçüde artmıştır (Gürcan\&Batu,2001).

\subsection{Amaç ve Yöntem}

$\mathrm{Bu}$ araştırmanın amacı, internetin gündelik yaşamımızda hızla kazandığı öneme paralel olarak online medya okuryazarlığı konusunun da giderek önem kazandığını haber siteleri üzerinden örnekleyerek ortaya koymaktır. Araştırmanın varsayımına göre, online haber sitelerinde yer alan çeşitli ürün, hizmet vs. reklamına ve satışına yönelik bannerlar, kullanıcıları asıl amaçlarından uzaklaştırarak tamamen tüketime yönlendiren farklı ortamlara taşımaktadır.

$\mathrm{Bu}$ çalışmada online haber anahtar sözcüğü google arama motoruna yazılarak bir arama yapılmıştır. Arama sonucunda ilk üç sıralamada yer alan sirasiyla http://www.Internethaber.com/ www.ntvmsnbc.com/ ve www.haberturk.com/ adlı haber siteleri 25-29 Ocak 2013 tarihleri arasında beş günlük süreyle izlenmiştir. İzleme için 08.0009.00, 14.00-15.00 ve 20.00-21.00 saatleri arası sabah, öğle ve akşam olmak üzere üç ayrı zaman dilimi belirlenmiştir. Bu zaman dilimleri içerisinde her üç site de sirayla ziyaret edilmiş ve sadece ana sayfalarında yer alan bannerlar incelenmiştir. Elde edilen bulgular araştırmanın varsayımına göre değerlendirilmiştir.

\subsection{Bulgular ve Değerlendirme}

Banner, web sitelerinin içine yerleştirilen reklam panolarıdır. Üzerine tıklandığında reklamverenin ana sayfasına ya da belirlemiş olduğu başka sayfaya yönlendirme yapılmaktadir (http://www.grafikerler.net/banner-nedir-banner-cesitleri-ve-olculerit6567.html). Böylelikle hem ziyaretçi sayısı hem de ürün veya hizmetin satışlarını artırmak amaçlanmaktadır.

En çok kullanılan banner formatları, standart banner reklamları ve zengin medya banner reklamları olmak üzere iki ana kategoriye ayrılmaktadır. Standart banner'lar, dünya 
genelinde en fazla kabul gören boyutlardan oluşmaktadır. Bunlar (http://www.internetreklamrehberi.com/banner-reklam-cesitleri.html) :

- Leaderboard: $728 \times 90$ piksel

- Full Banner: $468 \times 60$ piksel

- Half Banner: $234 \times 60$ piksel

- Skyscraper: 120 x 600 piksel

- Wide Skyscraper: 160 x 600 piksel

- Medium Rectangle: 300 x 250 piksel

- Vertical Rectangle: 240 x 400 piksel

- Rectangle: $180 \times 150$ piksel

Zengin medya banner'ları ise; animasyon, ses, video veya etkileşimli özellikler içeren banner çeşitleridir. Zengin medya banner uygulamalarının standart banner'lardan en önemli farkı, kullanıcı ile etkileşim kurmalarıdır. Bunlar aşağıdaki şekilde sıralanmaktadır (http://www.internetreklamrehberi.com/banner-reklam-cesitleri.html) :

- Rollover banner, imleci üzerine götürdüğ̈̈nüzde aşağıya doğru açılan banner çeşitidir. Kapalı konumdayken genel olarak standart banner boyutundadır fakat aşağıya doğru standart dişı bir boyutta açılabilir.

- Expandable banner, rollover banner ile aynı işleve sahip olan banner çeşitidir. Rollover banner ile arasındaki fark, kapalı konumdayken standart dışı bir formatta olabilmesi ve sadece aşağıda değil sola sağa ve bazı uygulamalarda yukarıya dahi açlabilmesidir.

- Sticky banner, normal şartlarda web sitesi sayfa şablonunun dış kısmında sol veya sağ alanda bulunan banner çeşitidir. Bu banner'ın "sticky" yani "yapışkan" olarak tanımlanmasındaki sebep, sayfa aşağı kaydırılsa da, banner'ın sabit olarak ekranda kalmasıdır (Diğer tüm banner çeşitleri sayfa aşağı kaydırıldığında yukarda kalır ve ekranda görülemez).

- Floating $A d$, web sitesi sayfaları "üzerine" yerleşim ve boyut bağımsız olarak açılabilen, animasyon, ses ve video içerebilen banner çeşitidir. Genel olarak, açtığınız sayfanın üzerinde herhangi bir alanda belirir ve ancak "kapat" butonu tıklayarak kapatılabilir aksi takdirde gezmek istediğiniz sayfada floating ad'in altında kalan herhangi bir alana tıklayamazsınız.

- Ad Corner, Floating Ad benzeri fakat görünüm ve etkileşim anlamında bazı farkları olan banner çeşitidir. Ad Corner'ın Floating Ad ile en önemli farkı, sayfaya ilk girdiğinizde kendiliğinden açılması, fakat "kapat" butonuna tıkladığınızda ufalarak sayfanın belirli bir alanına yerleşmesidir. Ad Corner'ı kapattıktan sonra, banner bir köşeye yerleşir ve alt sayfalarda da aynı konumda bulunmaya devam eder.

- Interstitial banner, sayfalarda gezinirken beliren ve site yapisindan tamamen farklı bir sayfa tasarımına sahip olan "sayfa arası" banner çeşitidir. Kullanıcı, herhangi bir alt sayfadan bir başka sayfaya tıkladığında, site yapısından farklı bir sayfa açılır ve Interstitial Banner görüntülenir. Bu sayfayı ancak "sayfayı geç" butonuna tıklayarak kapatır ve son tıkladığınız web sitesi sayfasını açabilirsiniz. Çoğu Interstitial banner çeşitinde, banner'ın görüntülenmesi için bir saniye aralığı vardır ve bu süre bittiğinde banner sayfası zaten kendiliğinden kapanır.

- Page skin, sayfa giydirme yapılan ve diğer tüm banner türlerinden farklı bir uygulamadır. Page skin uygulamalarında, web sitelerinin ana şablon yapısının dışında kalan sol ve sağ alandaki boşluklara reklam amaçlı görseller yerleştirilir. 
25-29 Şubat 2013 tarihleri arasında, http://www.ınternethaber.com/, www.ntvmsnbc.com/ve www.haberturk.com/ adlı haber sitelerinin izlenmesi sonucunda elde edilen bulgular ve açıklamaları Tablo 1'de yer almaktadır. Bannerlar sayılırken araştırmaya konu olan online haber sitelerinin kendi yayın grubunun bannerları dikkate alınmamıştır. Örneğin, internethaber yayın grubunda yer alan elmaelma, ntvmsnbc yayın grubunda yer alan Oley, Cnbc-e, startv ve Tvyo, Habertürk yayın grubunda yer alan Bloomberg HT ve HT Gazete Promosyonları vb. bannerlar sayılmamıştır.

Tablo 1: Online Haber Sitelerinin Ana Sayfalarında Yayınlanan Banner Sayısı

\begin{tabular}{|c|c|c|c|c|c|c|}
\hline \multirow[b]{2}{*}{ IZLEM TARIH } & \multicolumn{6}{|c|}{ BANNER SAYISI } \\
\hline & \multicolumn{2}{|c|}{ http://www.Internethaber.com/ } & \multicolumn{2}{|c|}{ www.ntvmsnbc.com/ } & \multicolumn{2}{|c|}{ www.haberturk.com/ } \\
\hline \multirow{3}{*}{25.01 .2013} & 7 & \multirow{3}{*}{9} & 5 & \multirow{3}{*}{6} & 4 & \multirow{3}{*}{5} \\
\hline & 7 & & 5 & & 4 & \\
\hline & 7 & & 5 & & 4 & \\
\hline \multirow{3}{*}{26.01 .2013} & 7 & \multirow{3}{*}{10} & 6 & \multirow{3}{*}{7} & 4 & \multirow{3}{*}{6} \\
\hline & 7 & & 6 & & 4 & \\
\hline & 8 & & 5 & & 4 & \\
\hline \multirow{3}{*}{ 27.01.2013 } & 8 & \multirow{3}{*}{12} & 6 & \multirow{3}{*}{7} & 4 & \multirow{3}{*}{5} \\
\hline & 8 & & 5 & & 4 & \\
\hline & 8 & & 4 & & 3 & \\
\hline \multirow{3}{*}{28.01 .2013} & 8 & \multirow{3}{*}{11} & 6 & \multirow{3}{*}{5} & 2 & \multirow{3}{*}{5} \\
\hline & 8 & & 5 & & 5 & \\
\hline & 8 & & 5 & & 3 & \\
\hline \multirow{3}{*}{29.01 .2013} & 7 & \multirow{3}{*}{11} & 4 & \multirow{3}{*}{4} & 3 & \multirow{3}{*}{5} \\
\hline & 8 & & 4 & & 4 & \\
\hline & 8 & & 4 & & 5 & \\
\hline
\end{tabular}

25.01.2013 Cuma tarihinde internethaber.com online haber sitesi ana sayfasında bütün izlem saatlerinde 7 tane banner olduğu görülmüştür. Toplamda ise; Renault Fluence, HP Electro World, Emlak Konut, Vermonth Saat, MNG Turizm, Google AdWords, Mizu, ETS Tur ve Garanti Bankası-HGS reklamı olmak üzere 9 farklı banner sayılmıştır. Renault Fluence, tam sayfa page skin olarak tasarlanmıştır. Ntvmcnbc.com online haber sitesi ana sayfasında bütün izlem saatlerinde 5 tane banner olduğu görülmüştür. Toplamda ise; UBS, Pegasus, Koleston, Airfrance, Sipru Oyun ve İpena olmak üzere 6 farklı banner sayılmıştır. Bunlardan Koleston ve İpena reklamı video formatındadır. Ayrıca Airfrance reklamı sabitken 120x90 üzerine gelindiğinde ise 500×250 piksel ölçülerinde olan expandable banner özelliğindedir. Haberturk.com online haber sitesi ana sayfasında bütün izlem saatlerinde 4 tane banner olduğu görülmüştür. Toplamda ise, Domino's Pizza, Akbaba Giyim, HSBC Advantage, Hyundai, ve Basın İlan Kurumu olmak üzere 5 farklı banner sayılmıştır. Bu sitenin ana sayfasında zengin medya bannerına rastlanmamıştır. Her üç sitede de zengin medya bannerları ve video formatındaki reklamlarının dışında kalan bannerlar sabit veya çeşitli animasyonlarla standart bannerlar olarak yer almıştır.

26.01.2013 Cumartesi tarihinde internethaber.com online haber sitesi ana sayfasında ilk iki izlem saatinde 7 , üçüncü izlem saatinde 8 tane banner yer aldığı görülmüştür. Toplamda ise; Vatan Bilgisayar, tatilbudur.com, Emlak Konut, Vermonth Saat, MNG Turizm, Google 
AdWords, Ets Tur, Mizu, Marcamarca ve Kervansaray Uludağ Hotel reklamı olmak üzere 10 farklı banner sayılmıştır. Vatan Bilgisayar tamsayfa, Ets Tur sol, Kervansaray Uludağ Otel hem sol hem sağ tarafta page skin olarak tasarlanmıştır. Ntvmcnbc.com online haber sitesi ana sayfasında ilk iki izlem saatinde 6 , üçüncü izlem saatinde 5 tane banner yer aldığ1 görülmüştür. Toplamda ise; UBS, Yapıkredi, Koleston, Airfrance, Sipru Oyun, HP Toner ve İpena olmak üzere 7 farklı banner sayılmıştır. Bunlardan Koleston ve İpena reklamı video formatındadır. Ayrıca Airfrance reklamı sabitken 120x90 üzerine gelindiğinde ise 500x250 piksel ölçülerinde olan expandable banner özelliğindedir. Haberturk.com online haber sitesi ana sayfasında bütün izlem saatlerinde 4 tane banner olduğu görülmüştür. Toplamda ise, Forex, British Time, Chevrolet, Basın İlan Kurumu, Akbaba Giyim ve bilyoner.com olmak üzere 6 farklı banner sayılmıştır. Bu sitenin ana sayfasında zengin medya bannerına rastlanmamıştır. Her üç sitede de zengin medya bannerları ve video formatındaki reklamlarının dışında kalan bannerlar sabit veya hareket kazandırılmış standart bannerlar olarak yer almıştır.

27.01.2013 Pazar tarihinde internethaber.com online haber sitesi ana sayfasında bütün izlem saatlerinde 8 tane banner yer aldığı görülmüştür. Toplamda ise; bilyoner.com, MNG Turizm, Mizu, Emlak Konut, Vermonth Saat, Google AdWords, Karadeniz FM, tatilbudur.com, Marcamarca, surveymonkey.com, Vatan Computer ve Netvarium reklamı olmak üzere 12 farklı banner sayılmıştır. Bilyoner.com arka sol, MNG Turizm arka sağ, Karadeniz FM arka sol, tatilbudur.com arka sağ, Vatan Computer arka sol ve Netvarium arka sağ tarafta page skin olarak tasarlanmıştır. Ntvmcnbc.com online haber sitesi ana sayfasında ilk izlem saatinde 6, ikinci izlem saatinde 5, üçüncü izlem saatinde 4 tane banner yer aldığ1 görülmüştür. Toplamda ise; HP, Koleston, Airfrance, UBS, Sipru Oyun, Halkbank Paraf ve İpena olmak üzere 7 farklı banner sayılmıştır. Bunlardan Koleston ve İpena reklamı video formatındadır. Ayrıca Airfrance reklamı sabitken 120x90 üzerine gelindiğinde ise 500x250 piksel ölçülerinde olan expandable banner özelliğindedir. Haberturk.com online haber sitesi ana sayfasında ilk iki izlem saatlerinde 4, üçüncü izlem saatinde 3 tane banner olduğu görülmüştür. Toplamda ise, Forex, British Time, Basın İlan Kurumu, bilyoner.com ve Akbaba Giyim olmak üzere 5 farklı banner sayılmıştır. Bu sitenin ana sayfasında zengin medya bannerına rastlanmamıştır. Her üç sitede de zengin medya bannerları ve video formatındaki reklamlarının dışında kalan bannerlar sabit veya hareket kazandırılmış standart bannerlar olarak yer almıştır.

28.01.2013 Pazartesi tarihinde internethaber.com online haber sitesi ana sayfasında bütün izlem saatlerinde 8 tane banner yer aldığı görülmüştür. Toplamda ise; Türk Hava Kurumu Üniversitesi, tatilbudur.com, HP Electroworld, Emlak Konut,Vermonth Saat, MNG Turizm, Google Adwords, Netvarium, Vatan Computer, HSBC Kredi ve ETS Tur reklamı olmak üzere 11 farklı banner sayılmıştır. Türk Hava Kurumu Üniversitesi arka sol, tatilbudur.com ve HSBC Kredi arka sağ tarafta page skin olarak tasarlanmıştır. Ntvmcnbc.com online haber sitesi ana sayfasında ilk izlem saatinde 6, ikinci ve üçüncü izlem saatinde 5 tane banner yer aldığ1 görülmüş̧tür. Toplamda ise; Güral Sapanca, HP ProBook, İpana, Airfrance ve Sipru Oyun olmak üzere 5 farklı banner sayılmıştır. Bunlardan İpena reklamı video formatındadır. Ayrıca Airfrance reklamı sabitken 120x90 üzerine gelindiğinde ise 500x250 piksel ölçülerinde olan expandable banner özelliğindedir. Haberturk.com online haber sitesi ana sayfasında ilk 
izlem saatinde 2, ikinci izlem saatinde 5, üçüncü izlem saatinde 3 tane banner olduğu görülmüştür. Toplamda ise, Halkbank Paraf, Basın İlan Kurumu, Domino Pizza, bilyoner.com ve gezinet.net olmak üzere 5 farklı banner sayılmıştır. Bu sitenin ana sayfasında zengin medya bannerına rastlanmamıştır. Her üç sitede de zengin medya bannerları ve video formatındaki reklamlarının dışında kalan bannerlar sabit veya hareket kazandırılmış standart bannerlar olarak yer almıştır.

29.01.2013 Salı tarihinde internethaber.com online haber sitesi ana sayfasında ilk izlem saatinde 8, ikinci ve üçüncü izlem saatinde 7 tane banner yer aldığ 1 görülmüştür. Toplamda ise; Türk Hava Kurumu Üniversitesi, HP Electroworld, Emlak Konut, Vermonth Saat, MNG Turizm, Google Adwords, Halbank Parafcard, tatilbudur.com, Mizu, Survey Monkey ve fun2win-tr.com reklamı olmak üzere 11 farklı banner sayılmıştır. Türk Hava Kurumu Üniversitesi arka sol, Halkbank Parafcard arka sağ tarafta page skin olarak tasarlanmıştır. Ntvmcnbc.com online haber sitesi ana sayfasında bütün izlem saatlerinde 4 tane banner yer aldığı görülmüştür. Toplamda ise; İpana, Airfrance, UBS ve Sipru Oyun olmak üzere 4 farklı banner sayılmıştır. Bunlardan İpena reklamı video formatındadır. Ayrıca Airfrance reklamı sabitken 120x90 üzerine gelindiğinde ise 500x250 piksel ölçülerinde olan expandable banner özelliğindedir. Haberturk.com online haber sitesi ana sayfasında ilk izlem saatinde 3, ikinci izlem saatinde 4, üçüncü izlem saatinde 5 tane banner olduğu görülmüştür. Toplamda ise, HP Toner, Forex, Basın İlan Kurumu, British Time, HSBC Kredi olmak üzere 5 farklı banner sayılmıştır. Bu sitenin ana sayfasında zengin medya bannerına rastlanmamıştır. Her üç sitede de zengin medya bannerları ve video formatındaki reklamlarının dışında kalan bannerlar sabit veya hareket kazandırılmış standart bannerlar olarak yer almıştır.

Araştırmanın sonucuna göre; internethaber.com online haber sitesi ana sayfasında her ziyarette ortalama 7,6 bannerla karşılaşıldığ1 görülmektedir. Günlük ortalama 10,6 farklı banner yayınlanmaktadır. Ntvmcnbc.com online haber sitesi ana sayfasında her ziyarette ortalama 5 bannerla karşılaşılmıştır. Günlük ortalama 5,8 farklı banner yayınlanmaktadır. Haberturk.com online haber sitesi ana sayfasında her ziyarette 3,8 bannerla karşılaşıldığ görülmektedir. Günlük ortalama 5,2 farklı banner yayınlanmaktadır. Internethaber.com online haber sitesi yayınlanan banner sayısında da ilk sırada yer almaktadır. Aynı şekilde google arama motorunda ikinci sırada yer alan ntvmcnbc.com online haber sitesi yayınlanan banner sayısında ikinci sırada, haberturk.com online haber sitesi ise google arama motorunda üçüncü sırada ve yayınlanan banner sayısında da üçüncü sırada yer almaktadır.

Araştırmanın sonucunda, aslında online haber sitelerinin ana sayfalarında banner reklamları için ayrılmış standart alanların olduğu ve bu alanların dışına pek taşılmadığ gözlemlenmiştir. Zengin medya bannerları ise, bu uygulamanın dışında kalmaktadır. Ziyaret edilen saat ve günlerde banner sayılarının farklı olması öncelikle sayfada zengin medya bannerlarının yer alıp almamasına bağlı olarak değişmektedir. Örneğin 25 Ocak Perşembe günü internethaber.com online haber sitesinin 08.00-09.00 saatleri arasındaki ziyarette Renault Fluence reklamının arkada page skin olarak tam sayfa yer aldığı görülmektedir. 27 Ocak Pazar günü aynı saatlerde arka sol tarafta bilyoner.com, arka sağ tarafta ise MNG Turizm'in bannerları ayrı ayrı yer almaktadır. Banner sayılarının farklı olmasında ikinci etken sitelerin kendi yayın grubuna ait bannerlarının sayılmamasından kaynaklanmaktadır. 
Örneğin 25 Ocak Perşembe günü ntvmcnbc.com online haber sitesinin 14.00-15.00 saatleri arasındaki ziyarette toplamda 8 banner görülmüştür ancak bunlardan üçü ntvmcnbc yayın grubunda yer alan tvyo, cnbc-e ve oley reklamlarıdır. Bunlar araştırma dışı bırakılarak toplamda 5 banner olduğu belirtilmiştir. Üçüncü etken ise, 300x250 piksel ölçülerinde alt alta bulunan 2 banner alanına bazen 300x500 piksellik daha büyük boyutta tek bir banner yerleştirildiği görülmektedir. Dolayısıyla tüm bunlar, online haber sitelerinin ana sayfalarında banner reklamları için ayrılmış alanların standart olmasına rağmen ziyaret edilen saat ve günlerde banner sayılarının farklı olmasında etken olarak belirlenmiştir.

Ayrıca genel olarak online haber sitelerininin ana sayfalarında zengin medya bannerlarının çok fazla yer almadığı çoğunlukla standart bannerlara yer ayrıldığı gözlemlenmiştir. Haberturk.com online haber sitesi ana sayfasında izlem süresince hiçbir zengin medya uygulamasına rastlanmazken ntvmcnbc.com online haber sitesindeki Airfrance reklamının expandable banner biçiminde sürekli olarak yer aldığı gözlemlenmiştir. Internethaber.com online habersitesi ana sayfasında ise farklı tarihlerde farklı ürünlerin bannerları page skin biçiminde yayınlanmıştır. Araştırmanın sonucuna göre zengin medya bannerlarının yoğun olarak kullanıldığı alanlar haber sitelerinin iç sayfaları ya da iç sayfa geçişleridir.

\section{SONUÇ}

İletişim teknolojilerideki gelişmeler okuryazarlık kavramının içeriğinin genişlemesine yol açmıştır. Temelde yazılı metinleri okuyabilmek ya da yazabilmek anlamında kullanılan okuryazarlık günümüzde medya araçları yoluyla iletilen tüm yazılı, görsel ve de işitsel mesajların çözümlenebilmesi anlamında kullanılmaktadır. Medya okuryazarlığı kavramının teknolojik gelişmeler sonucu içerik olarak genişlemesiyle beraber konuya ilişkin çeşitli alt başlıklar oluşmuştur. Bunlardan biri de internetle birlikte hayatımıza giren online medya okuryazarlığıdır. Sahip olduğu ve sunduğu tüm kolaylıklar nedeniyle online medya çoğunlukla geleneksel medyaya alternatif bir konumda görülmektedir. Yapılan araştırmalar kullanıcıların birçoğunun haberleri internet üzerinden takip ettiklerini göstermektedir.

Gerek geleneksel olsun gerek online olsun tüm medya kuruluşları gibi haber medyası da ticari kaygılar taşımaktadır. Bu kaygılar öncelikle satış ve reklam gelirleri yoluyla giderilmeye çalışılmaktadır. Fakat geleneksel medyada yer alan reklamlar sadece kendisine ayrılan yer ve zamanla sinırliyken online medyada ise bu durum çok daha farklı gelişmektedir. $\mathrm{O}$ an sadece üzerine tıklanan bir banner, kullanıcıları asıl amaçlarından uzaklaştırarak tamamen tüketime yönlendiren, yer ve zaman sınırlaması olmayan başka ortamlara taşıyabilmektedir.

Yapılan araştırmanın sonucu göre; online haber sitelerinin ana sayfalarında bannerlar için genellikle standart alanlar belirlenmiştir ve bu alanlarda sürekli olarak yayın grubunun kendisine ait ya da farklı bir reklam verene ait ürün, hizmet vs. bannerı yayınlanmaktadır. Diğer haberlerle zıt renkler, çeşitli sloganlar, efekt ve hareketler yoluyla kullanıcıların dikkati bu bannerlar üzerine çekilmeye çalışılmaktadır. Burada önemli olan kullanıcıların bunun farkında ve bilincinde olması, haber edinmek amacıyla ziyaret ettikleri bir sitede bannerların dikkat dağıtmasına ve öncelikli amacın önüne geçmesine izin vermemeleri gerektiğidir. Bu 
konudaki farkındalık ve bilinç ise, sadece online medya okuryazarlığı yoluyla kazandırılabilecek bir edim olarak görülmektedir.

\section{KAYNAKLAR}

Buckingham, D. (2003). Media Education: Literacy, Learning and Contemporary Culture. Cambrage: Polity.

Federov, A. (2003). Media Education and Media Literacy: Experts' Opinions. Unesco: A Media Education Curriculum for Teacher's in the Mediterranean. (Çevirimiçi) http://www.europeanmediaculture.org. 30 Ekim 2012.

Frechette, J.D. (2002). Developing Media Literacy in Cyberspace: Pedagogy and Critical Learning for the Twenty-First-Century Classroom. Westport, CT, USA: Greenwood Press.

Gürcan, İ., Batu, Ç.(2001). Haber Sitelerinde İçerik Kalitesine Yönelik Bir Analiz. VIII. Türkiye'de İnternet Konferansı, İstanbul: Askeri Müze. (Çevirimiçi) www.inettr.org.tr/inetconf8/bildiri/97.doc.

Hobbs, R. (1997): Expanding the Concept of Media Literacy. Media Literacy in the Information Age: Current Perspektives. Robert W.Kubey (Ed). New Brunswick \& London: Transaction Publishers. p.163-183.

İnan, A. (2000). Internet El Kitabı. İstanbul: Sistem Yayıncılık.

Kelleher, T. (2007). Public Relations Online: Lasting Concepts for Changing Media. Thousand Oaks, London, New Delhi: Sage Publications.

Kellner, D., Share, J. (2005). Toward Critical Media Literacy: Core Concepts, Debates, Organizations and Policy. Discourse: Studies in the Cultural Politics of Education. Vol. 26, No. 3. pp.369-386.

Livingstone, S. (2004). Media Literacy and the Challenge of New Information and Communication Technologies. The Communication Review. Vol.7, No:1. pp.3-14.

Philips, D. (2001). PR in Practice Series: Online Public Relations. Kogan Page.

Pungente, J. (ty). Canada's Key Concepts of Media Literacy. Center for Media Literacy. (Çevirimiçi) http://www.medialit.org/reading-room/canadas-key-concepts-media-literacy. 30 Ekim 2012.

Sezen, D. (2011). Katıllma Kültürün Oluşumunda Yeni Medya Okuryazarlı̆̆ı: ABD ve Türkiye Örnekleri. İstanbul üniversitesi Sosyal Bilimler Enstitüsü Radyo, Televizyon ve Sinema Anabilim Dalı Yayınlanmamış Doktora Tezi. İstanbul.

Taşkıran, N.Ö. (2007). Medya Okuryazarlğ̆ına Giriş. İstanbul: Beta Basım Yayın

Intranet ve Extranet Nedir? (Çevirimiçi) http://www.e-ticaret.co.uk/intranet-ve-extranet-nedir/. 2 Kasim 2012.

İçerik Yönetim Sistemi. İnönü Üniversitesi Bilgi İşlem Daire Başkanlığı. (Çevirimiçi) http://iys.inonu.edu.tr/?web=bidb\&mw=54. 13 Kasım 2012. 
Blog Nedir, Nasıl Kurulmuştur?. Katalog. (Çevirimiçi) http://www.ekatalog.com.tr/blog-nedir.html. 2 Kasim 2012.

Medya Okuryazarlığı Nedir?. RTüK Medya Okuryazarlı̆̆ı. ( (Çevirimiçi) http://www.medyaokuryazarligi.org.tr/nedir.html. 03 Aralık 2012.

The Key Concepts. Median ABC: Introduction into Media Education. (Çevirimiçi) http://www.medienabc.org/page5/page7/page7.html. 30 Ekim 2012.

Medya Okuryazarlığı Kamu Spotu. (Çevirimiçi) http://www.ajans01.com/video/25-medya-okuryazarligi-kamu-spotu.html. 06 Aralık 2012.

Banner Nedir? Banner Çeşitleri ve Ölçüleri. (Çevirimiçi) http://www.grafikerler.net/banner-nedirbanner-cesitleri-ve-olculeri-t6567.html. 3 Ocak 2013.

Banner Reklam Çeşitleri. Internet Reklam Rehberi. (Çevirimiçi) http://www.internetreklamrehberi.com/banner-reklam-cesitleri.html. 3 Ocak 2013.

Neden Medya Okuryazarlığı Dersi?. RTÜK Medya Okuryazarlı̆̆ı. (Çevirimiçi) http://www.medyaokuryazarligi.org.tr/neden.html). 22 Nisan 2013. 